\title{
An HMG I/Y-containing repressor complex and supercoiled DNA topology are critical for long-range enhancer-dependent transcription in vitro
}

\author{
Rajesh Bagga and Beverly M. Emerson ${ }^{1}$ \\ Regulatory Biology Laboratory, The Salk Institute for Biological Studies, La Jolla, California 92037 USA
}

The 3' enhancer of the T cell receptor $\alpha$-chain (TCR $\alpha)$ gene directs the tissue- and stage-specific expression and $V(D) J$ recombination of this gene locus. Using an in vitro system that reproduces TCR $\alpha$ enhancer activity efficiently, we show that long-range promoter-enhancer regulation requires a $T$ cell-specific repressor complex and is sensitive to DNA topology. In this system, the enhancer functions to derepress the promoter on supercoiled, but not relaxed, templates. We find that the TCR $\alpha$ promoter is inactivated by a repressor complex that contains the architectural protein HMG I/Y. In the absence of this repressor complex, expression of the TCR $\alpha$ gene is completely independent of the $3^{\prime}$ enhancer and DNA topology. The interaction of the T cell-restricted protein LEF-1 with the TCR $\alpha$ enhancer is required for promoter derepression. In this system, the TCR $\alpha$ enhancer increases the number of active promoters rather than the rate of transcription. Thus, long-range enhancers function in a distinct manner from promoters and provide the regulatory link between repressors, DNA topology, and gene activity.

[Key Words: TCR genes; transcription; enhancers; HMG I/Y; derepression; DNA topology]

Received December 27, 1996; revised version accepted January 14, 1997.

The widespread importance of long-range promoterenhancer interactions in tissue-specific and developmentally regulated gene expression has been documented extensively. Some well-known examples include the immunoglobulin, $\beta$-globin, insulin, $\beta$-interferon, $\alpha$-fetoprotein, ovalbumin, and $\mathrm{T}$-cell receptor genes, as well as the Drosophila alcohol dehydrogenase Adh, fushi tarazu, and ecdysone-regulated glue genes (for review, see Wasylyk 1988). These studies have yielded a wealth of information about enhancer-dependent transcription, but they have not provided mechanistic data to explain how these control elements actually work. For example, it is currently unknown how a gene must be packaged in the nucleus for natural enhancers to function. In this regard, the requirement for chromatin structure to generate long-range transcriptional regulation has been demonstrated in vitro using reconstituted DNA templates (Laybourn and Kadonaga 1992; Barton and Emerson 1994). It also remains to be determined how promoters communicate with distal enhancers. Several models have been proposed: DNA looping by the association of proteins bound at distal sites, DNA tracking by protein translocation, and long-range interactions affected by DNA topology (for review, see Ptashne 1986; Wang and

${ }^{1}$ Corresponding author.

E-MAIL emerson@salk.edu; FAX (619) 535-8194.
Giaever 1988; Rippe et al. 1995). Evidence supporting each model has been demonstrated in different systems. In terms of DNA topology, the critical role of DNA architectural proteins, such as high mobility group $\mathrm{I} / \mathrm{Y}$ (HMG I/Y) and integration host factor (IHF) among others, in the regulation of transcription and recombination through the formation of higher-order protein-DNA complexes is particularly germane (for review, see Bustin and Reeves 1996). For example, HMG I/Y is required to generate a multicomponent complex within the interferon- $\beta$ promoter in response to viral infection for maximal synergistic activation of the gene, presumably by changing the local DNA structure (Falvo et al. 1995). Alterations in global DNA topology can substantially affect the requirements of a gene for general transcription initiation factors (Parvin and Sharp 1993). Another compelling question is whether enhancers regulate promoters by activation or derepression. The prevailing view is that enhancers function by increasing the local concentration of transcriptional activators in the vicinity of the promoter through DNA looping rather than by operating in an entirely distinct manner from upstream promoter elements. However, evidence exists showing that the primary role of enhancers injected into mouse preimplantation embryos is to relieve promoter repression (Majumder et al. 1993). Thus, open questions remain concerning the nuclear structure required to gen- 
erate an enhancer-responsive gene including the role of architectural proteins, the nature of promoter-enhancer communication (looping, tracking, topology, or a combination thereof), and the functional consequences of this long-range interaction (activation or derepression).

One well-characterized system in which to examine these issues is the tissue-specific T-cell receptor $\alpha$-chain $(\mathrm{TCR} \alpha)$ gene. This gene undergoes $V(D) J$ recombinasemediated rearrangement at a discrete stage of $T$-cell development in a process that requires the TCR $\alpha$ enhancer (Strominger 1989; Capone et al. 1993). Once productively rearranged, the TCR $\alpha$ gene is regulated tissue specifically by the $3^{\prime} \alpha$ enhancer from distances $\leqslant 50 \mathrm{~kb}$. The minimal enhancer consists of $116 \mathrm{bp}$ that interacts with four proteins, cAMP response element binding/activating transcription factor (CREB/ATF), lymphoid enhancer-binding factor 1 (LEF-1), polyoma enhancer binding protein (PEBP2 $\alpha$ ), and $E$ twenty-six transforming virus protein-1 (Ets-1), and functions in a context-dependent manner (for review, see Leiden 1993). The lymphoid-restricted factor LEF-1 contains an HMG-binding domain (Waterman et al. 1991) and has been shown to act as an architectural factor by its ability to induce a sharp bend in the enhancer that brings the other adjacently bound proteins into close juxtaposition to produce a functional complex (Giese et al. 1992, 1995). How the protein-enhancer complex then regulates its cognate $V_{\alpha}$ promoter at a distance is unknown. To examine the mechanistic processes involved in these long-range interactions, we have developed an in vitro system that reproduces accurately distal enhancer-dependent transcriptional regulation of cloned $\mathrm{TCR} \alpha$ genes using protein extracts from $\alpha / \beta$-expressing Jurkat T cells.

Here we show that long-range promoter-enhancer communication does not require a separate chromatin assembly step but is strongly dependent on DNA topology. TCR $\alpha$ genes must exist in a supercoiled topology to be transcribed efficiently in the presence of the $3^{\prime}$ enhancer. When the gene is relaxed, transcription is abolished by the enhancer. However, if the enhancer is deleted, the relaxed genes are highly expressed. This indicates that a critical aspect of enhancer function is to regulate promoter activity by sensing changes in levels of template superhelicity to insure that genes are active when supercoiled and inactive when relaxed. In this system, TCR $\alpha$ enhancer-mediated gene regulation requires the action of a repressor complex that binds to topologydependent DNA structures. This complex is composed of T-cell factors and the architectural protein $\mathrm{HMG} \mathrm{I} / \mathrm{Y}$, which is required to generate an enhancer-responsive DNA topology. The enhancer functions by derepression of the supercoiled $V_{\alpha}$ promoter in a process that may involve modulating DNA structure to regulate the binding affinity of the HMG I/Y-repressor complex. Mutations that abolish LEF-1 binding to the enhancer eliminate promoter derepression completely at a distance of $2.5 \mathrm{~kb}$. We find that the TCR $\alpha$ enhancer increases the number of active promoters rather than the rate of transcription. Interestingly, in the absence of repressors, expression of TCR $\alpha$ genes is independent of the $3^{\prime}$ en- hancer and DNA topology. Thus, enhancers function with a specialized class of repressor proteins to regulate promoter activity on the basis of DNA topology and an

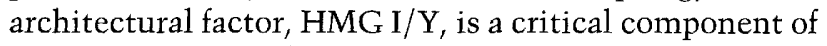
the repressor complex.

\section{Results \\ Distal enhancer-dependent RNA polymerase II transcription in vitro}

Previously, we have shown that in vitro transcription of cosmids containing the chick $\beta$-globin gene within its $40-\mathrm{kb}$ chromosomal locus is dependent on the action of an erythroid-specific enhancer residing $2 \mathrm{~kb} 3^{\prime}$ of the promoter. In this system, the DNA was incorporated into synthetic nuclei using Xenopus egg extracts in the presence of stage-specific erythroid proteins. This resulted in the assembly of DNA into chromatin and subsequent encapsulation by a nuclear membrane (Barton and Emerson 1994). Because a variety of cloned genes as naked DNA do not normally display distal enhancerdependent expression under standard in vitro transcription conditions, our results and those of others (Laybourn and Kadonaga 1992; Schild et al. 1993) suggested that a nucleosomal structure is required. We were interested in characterizing the nature of this structure and how complex it had to be to reproduce tissue-specific enhancer function at a distance. As a first step, we devised conditions in which cloned mouse TCR $\alpha$-chain reporter genes are transcribed in a distal enhancer-dependent manner in a soluble in vitro transcription system without the need for a separate nucleosome assembly step. This system is derived from human Jurkat $\mathrm{T}$ cells that normally express the endogenous $\mathrm{TCR} \alpha / \beta$ genes. The TCR $\alpha$ DNA template used in these studies, pTCR1700TCRen, contains the mouse $V_{\alpha} 11.1$ promoter region from -1600 , a $2.5-\mathrm{kb}$ chloramphenicol acetyltransferase (CAT) reporter gene, and 237 bp of 3 '-flanking sequences including the minimal TCR $\alpha$ enhancer. The $3^{\prime}$ enhancer deletion pTCR1700 was derived from the parental plasmid pTCR 1700TCRen. These templates have been characterized extensively by transfection studies in other laboratories and $V_{\alpha} 11.1$ promoter activity was shown to be completely enhancer dependent in vivo (Winoto and Baltimore 1989; Kingsley and Winoto 1992). The 237-bp TCR $\alpha$ enhancer binds to five proteins: the ubiquitous CREB/ATF and tissue-restricted LEF-1, Ets-1, PEBP2 $\alpha$, and GATA-3, which together are essential for its T-cell-specific activity. Very little information is available concerning the $V_{\alpha} 11.1$ promoter except that it does not contain a TATA motif and is regulated positively by members of the $\mathrm{Spl}$ family, including $\mathrm{Sp} 2$ and Sp3 (Kingsley and Winoto 1992). A diagram of this template and the protein-DNA interaction pattern on the promoter and enhancer regions is shown in Figure 1A.

A transcriptional analysis of pTCR1700TCRen and its enhancer-minus derivative pTCR 1700 in TCR $\alpha / \beta$-expressing Jurkat T-cell transcription extracts demonstrated that TCR $\alpha$ gene expression is entirely enhancer- 
A

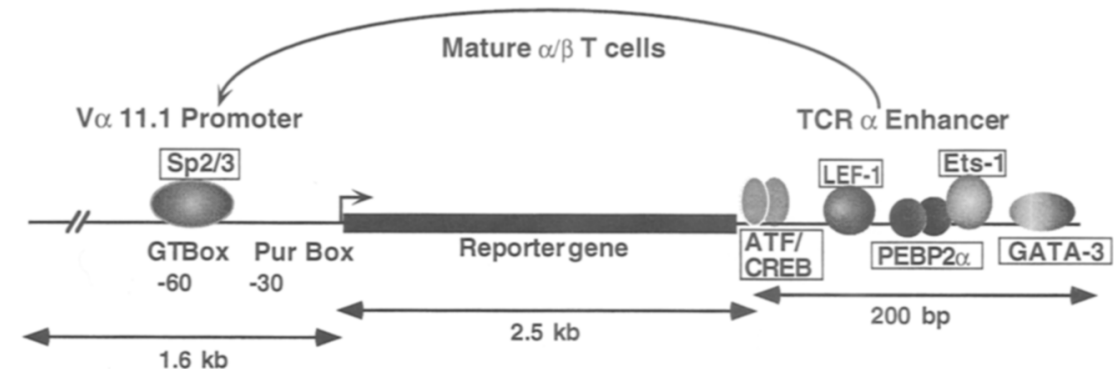

B

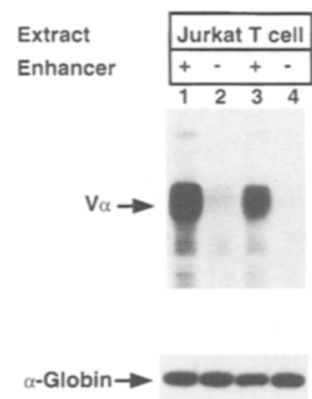

C

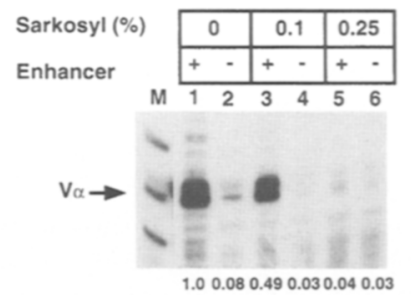

D

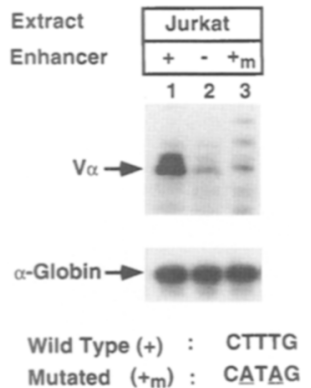

Figure 1. Distal enhancer-dependent transcription of the $\mathrm{T}$ cell receptor $\alpha$-chain gene in vitro. $(A)$ Diagram of the TCR $\alpha$ CAT reporter construct used in the in vitro transcription studies. The designated protein-DNA-binding sites on the $V_{\alpha} 11.1$ promoter and TCR $\alpha$ enhancer are summarized from data presented elsewhere (for review, see Leiden 1993). (B) In vitro transcription of TCR $\alpha$ genes in Jurkat protein extracts. Supercoiled TCR $\alpha$ gene plasmids (pTCR1700TCRen + enhancer, or pTCR1700 - enhancer) were incubated at a concentration of $10 \mu \mathrm{g} / \mathrm{ml}$ with transcription extracts prepared from Jurkat $\mathrm{T}$ cells as described in Materials and Methods. TCR $\alpha$ gene + enhancer (lanes 1,3); -enhancer (lanes 2,4). (Bottom) $25 \mathrm{ng}(0.5$ $\mu \mathrm{g} / \mathrm{ml})$ of a human $\alpha$-globin plasmid was included in each reaction as an internal transcription and recovery control. (C) Enhancer-dependent TCR $\alpha$ gene expression under single-round transcription conditions. Supercoiled TCR $\alpha$ plasmid templates pTCR1700TCRen and pTCR1700 were incubated with Jurkat protein extracts in transcription buffer lacking rNTPs (see Materials and Methods) for 5 min at $30^{\circ} \mathrm{C}$ to establish a preinitiation complex at the $V_{\alpha}$ promoter. Longer incubation times resulted in loss of enhancer-dependent transcription. All four rNTPs were then added for $90 \mathrm{sec}$ followed by the addition of water (lanes 1,2), $0.1 \%$ Sarkosyl to prevent reinitiation (lanes 3,4), or 0.25\% Sarkosyl (lanes $5,6)$. The numbers below each lane represent the fold variation in TCR $\alpha$ RNA synthesis under specific reaction conditions. $(D)$ Site-directed mutagenesis of the LEF-1-binding site in the TCR $\alpha$ enhancer abrogates enhancer-dependent transcription in vitro. Supercoiled TCR $\alpha$ gene plasmids (pTCR1700TCRen + enhancer, pTCR1700TCRmten ${ }_{m}$ mutant enhancer, or pTCR1700 - enhancer) were transcribed with Jurkat extracts as in B. TCR $\alpha+$ enhancer (lane 1); TCR $\alpha$ - enhancer (lane 2); TCR $\alpha+{ }_{m}$ mutant enhancer (lane 3). (Bottom) $25 \mathrm{ng}(0.5 \mu \mathrm{g} / \mathrm{ml})$ of a human $\alpha$-globin plasmid was included in each reaction as an internal transcription and recovery control. Sequences of both wild-type and mutated LEF-1-binding sites with mutated residues underlined is shown below.

dependent in this in vitro system. As shown in Figure 1B, $V_{\alpha}$ promoter activity is regulated efficiently by the TCR $\alpha$ enhancer in CAT reporter constructs when transcribed in Jurkat $\mathrm{T}$ cell extracts (lanes 1,3 ), but expression is abolished if the enhancer is deleted (lanes 2,4). In contrast, transcription of a human $\alpha$-globin reporter gene that was included as an internal control is uniform in all reactions. To assess the effect of the TCR $\alpha$ enhancer under single-round transcription conditions, we performed an experiment in the presence of low concentrations of the detergent Sarkosyl, which can distinguish specific steps in the initiation process (Hawley and Roeder 1987). As shown in Figure 1C, using a Sarkosyl concentration of $0.1 \%$ to prevent reinitiation, there are two rounds of enhancer-dependent transcription in this in vitro system (cf. lane 1 with lane 3). A range of Sarkosyl concentrations were tested: $0.01 \%, 0.05 \%, 0.1 \%$, $0.2 \%, 0.25 \%$, and $0.3 \%$, with RNA synthesis leveling off at $0.1 \%$ indicating that single-round transcription conditions had been reached (data not shown). Interestingly, the level of enhancer-mediated transcription is more than an order of magnitude and remains constant in both single and double rounds of initiation (cf. lanes 1 and 2 with lanes 3 and 4). At higher concentrations of Sarkosyl,
$0.25 \%$, transcription is abolished completely (lanes 5,6$)$. These results suggest that as the increase in transcription levels in the presence of the TCR $\alpha$ enhancer does not change with multiple rounds of initiation, the enhancer functions by increasing the number of active promoters instead of changing the rate of RNA polymerase II (Pol II) loading onto a constant number of $V_{\alpha}$ promoters. This is in agreement with previous in vitro studies using a yeast RNA Pol I enhancer (Schultz et al. 1993) and in recent experiments using Pol II enhancers in transient and stable expression assays (Walters et al. 1995).

\section{LEF-1 regulates long-range enhancer-dependent TCR $\alpha$ gene transcription in vitro}

The T-lymphocyte restricted factor LEF-1 has been shown to regulate TCR $\alpha$ enhancer function in a contextdependent manner and to induce a significant bend in local DNA structure. This is thought to coordinate the assembly of a specific higher-order complex by facilitating the interactions between proteins bound at adjacent sites within the enhancer (for review, see Grosschedl 1995). To analyze the role of LEF-1 in enhancer-dependent transcriptional regulation, we examined the effect 
of mutations that abolish LEF-1 binding to the TCR $\alpha$ enhancer using our in vitro system. As shown in Figure $1 \mathrm{D}, \mathrm{TCR} \alpha$ plasmids are transcribed efficiently in the presence of the enhancer in Jurkat T cell extracts (lane 1), but expression is abolished by two-point mutations that eliminate LEF-1 interaction with the enhancer (lane 3) as effectively as when the entire enhancer is deleted (lane 2). Thus, LEF-1 has a critical role in TCR $\alpha$ gene transcription when it is enhancer-dependent in Jurkat extracts and is able to affect gene expression at a distance of $2.5 \mathrm{~kb}$ in vitro. These results confirm previous in vivo studies by demonstrating that when bound to the TCR $\alpha$ enhancer, LEF-1 is required for high level promoter activity. Moreover, the absolute requirement of LEF-1-enhancer interaction for efficient transcription in vitro strongly substantiates the use of this system as a valid approach to analyze the mechanism of long-range promoter-enhancer regulation in detail.

\section{The TCR $\alpha$ enhancer regulates transcription by promoter derepression}

The observation that TCR $\alpha$ gene transcription was abolished completely in the absence of the enhancer when incubated with Jurkat extracts (Fig. 1B) suggested at least two possible mechanisms: enhancers either activate weak promoters or derepress strong promoters. To provide further information on this question, we examined TCR $\alpha$ gene expression in the presence and absence of the enhancer using a range of Jurkat extract protein concentrations to assess the effect of this element under optimal and suboptimal transcription conditions. As shown in Figure 2A, transcription with low to optimal concentrations $(2-7 \mu \mathrm{g} / \mathrm{ml})$ of Jurkat extract resulted in similar levels of RNA synthesis from TCR $\alpha$ genes whether or not the enhancer was present (cf. lanes 1-3 with lanes $5-7)$. Interestingly, within this range TCR $\alpha$ genes lacking the enhancer are transcribed more efficiently than templates linked to the enhancer $(4 \mu \mathrm{g} / \mathrm{ml}$; lane 2 vs. lane 6). We have observed this consistently and feel that it is attributable to the enhancer acting as a competitive inhibitor of transcription at limiting concentrations of extract. However, when higher concentrations of Jurkat extract were used $(10 \mu \mathrm{g} / \mathrm{ml}), \mathrm{TCR} \alpha$ gene transcription decreased slightly in the presence of the enhancer but was abolished completely in its absence (cf. lane 4 with lane 8 ). The $\alpha$-globin internal control is also somewhat decreased at this protein concentration but no reaction selectivity is observed (lanes 4,8 ). Taken together, these results suggest that a repressor activity is present at higher concentrations of the Jurkat extract that acts selectively on the $V_{\alpha}$ promoter when unlinked to the enhancer. In addition, over a range of transcriptional efficiencies, the $V_{\alpha}$ promoter appears not to be up-regulated by the distal TCR $\alpha$ enhancer but instead is derepressed.

As a control, we examined TCR $\alpha$ gene expression in vitro using a range of HeLa extract protein concentrations. HeLa extracts contain high concentrations of general transcription factors and express most cloned pol II genes in an efficient but unregulated manner. Thus, transcription of TCR $\alpha$ gene plasmids in a HeLa extract is a measure of general promoter strength but does not reflect the regulation of the endogenous $\operatorname{TCR} \alpha$ gene in HeLa fibroblasts, which is unrearranged, chromatinized, and inactive. As shown in Figure 2B, transcriptional efficiencies of TCR $\alpha$ genes in the presence or absence of the enhancer were almost identical at each titration point, with one exception (lanes 12,17). Even at very high concentrations of HeLa extract $(15-30 \mu \mathrm{g} / \mathrm{ml})$, no preferential repression of the enhancerless TCR $\alpha$ gene was observed (data not shown). This indicates that the TCR $\alpha$ enhancer does not increase the level of $V_{\alpha}$ promoter activity over a wide range of HeLa extract concentrations and that enhancer-dependence is only apparent in Jurkat extracts that contain the putative repressor functioning in a $T$-cell protein context.
Figure 2. Specific repression of enhancerless TCR $\alpha$ genes in Jurkat T-cell extracts. $(A)$ In vitro transcription of $\mathrm{TCR} \alpha$ genes using a titration of Jurkat T-cell extract. Supercoiled TCR $\alpha$ gene plasmids (pTCR1700TCRen or pTCR1700) were incubated with various amounts of a Jurkat extract and transcribed as described in Materials and Methods. Jurkat extract: $2 \mu \mathrm{g} / \mathrm{ml}+$ enhancer (lane 1 ), -enhancer (lane 5); $4 \mu \mathrm{g} / \mathrm{ml}+$ enhancer (lane 2), -enhancer (lane 6); $7 \mu \mathrm{g} / \mathrm{ml}+$ enhancer (lane 3), -enhancer (lane 7); $10 \mu \mathrm{g} / \mathrm{ml}+$ enhancer (lane 4), -enhancer (lane 8). (Bottom) $25 \mathrm{ng}(0.5 \mu \mathrm{g} / \mathrm{ml})$ of a human $\alpha$-globin plasmid was included in each reaction as an internal control. Relative transcription (in arbitrary units) was determined by PhosphorImager analysis of the gel. (B) In vitro transcription of TCR $\alpha$ genes using a titration of HeLa fibroblast extract. Supercoiled TCR $\alpha$ gene plasmids (pTCR1700TCRen or pTCR 1700) were incubated with various amounts of a HeLa extract and transcribed as described above. HeLa extract: $2 \mu \mathrm{\mu g}$ $\mathrm{ml}+$ enhancer (lane 9), -enhancer (lane 14); $4 \mu \mathrm{g} / \mathrm{ml}+$ enhancer (lane 10), -enhancer (lane 15); $7 \mu \mathrm{g} / \mathrm{ml}+$ enhancer (lane 11), -enhancer (lane 16); $10 \mu \mathrm{g} / \mathrm{ml}+$ enhancer (lane 12), -enhancer (lane 17);15 $\mathrm{gg} / \mathrm{ml}+$ enhancer (lane 13), -enhancer (lane 18). (Bottom) $25 \mathrm{ng}$ (0.5 $\mu \mathrm{g} / \mathrm{ml}$ ) of a human $\alpha$-globin plasmid was included in each reaction as an internal control. Relative transcription (in arbitrary units) was determined by PhosphorImager analysis of the gel.

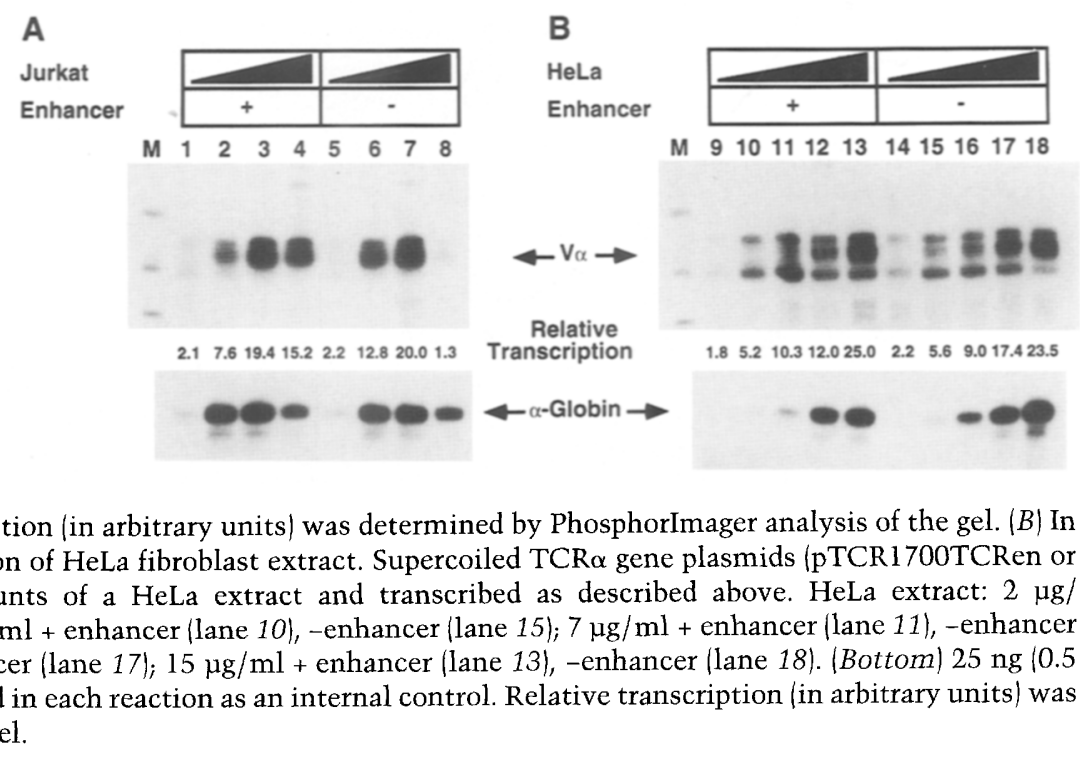
Jurkat$$
\text { M }
$$ 
A

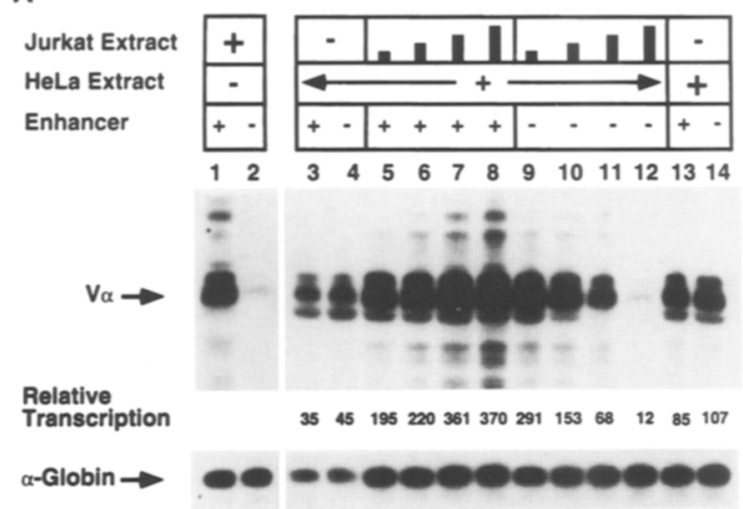

B

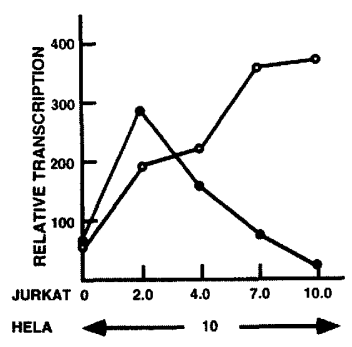

Figure 3. A dominant repressor in Jurkat extracts confers enhancer-dependent transcription of TCR $\alpha$ genes on complementation of HeLa extracts. (A) Complementation of $\mathrm{HeLa}$ transcription extract with varying amounts of Jurkat T-cell extract. In vitro transcription of supercoiled pTCR1700TCRen or pTCR1700 plasmids was performed as described in Materials and Methods. Jurkat extract $(10$ $\mu \mathrm{g} / \mathrm{ml}$ ): +enhancer (lane 1), -enhancer (lane 2). HeLa extract $(10 \mu \mathrm{g} / \mathrm{ml})$ : +enhancer (lane 3,) -enhancer (lane 4); HeLa extract $(15 \mu \mathrm{g} / \mathrm{ml})$ : +enhancer (lane 13), -enhancer (lane 14). HeLa extract $(10 \mu \mathrm{g} / \mathrm{ml})$, complemented with Jurkat extract at $2 \mu \mathrm{g} / \mathrm{ml}$ ): +enhancer (lane 5), -enhancer (lane 9); $(4 \mu \mathrm{g} / \mathrm{ml})+$ enhancer (lane 6), -enhancer (lane 10$) ;(7 \mu \mathrm{g} / \mathrm{ml})+$ enhancer

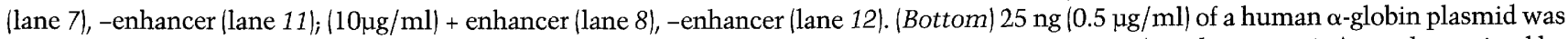
included in each reaction as an internal control for transcription and recovery. Relative transcription (in arbitrary units) was determined by PhosphorImager analysis of the gel. (B) A plot of the relative transcriptional activities (in arbitrary units) of the pTCR1700TCRen (O) and pTCR1700 (O) plasmids vs. the concentration of repressor-containing Jurkat extract used to complement a constant amount of HeLa extract.

To further substantiate the role of a repressor in mediating enhancer-regulated TCR $\alpha$ gene transcription in Jurkat extracts, we performed an experiment in which a suboptimal concentration of HeLa extract was mixed with increasing amounts of a Jurkat extract to determine whether the addition of the repressor and other $T$ cell proteins could confer enhancer-dependent transcription in a HeLa factor environment. As shown in Figure 3A, TCR $\alpha$ gene transcription with low amounts of HeLa extract $(10 \mu \mathrm{g} / \mathrm{ml}$; lanes 3,4$)$ is increased significantly by the addition of Jurkat extracts over a range of $2-10 \mu \mathrm{g} / \mathrm{ml}$ in the presence of the enhancer (lanes 5-8). A similar increase is observed in the absence of the enhancer over a narrower Jurkat concentration range $2-4 \mu \mathrm{g} / \mathrm{ml}$ (lanes $9,10)$ until a critical repressor concentration is reached at $7-10 \mu \mathrm{g} / \mathrm{ml}$, when transcription is decreased markedly relative to enhancer-containing templates until it is inactivated completely (cf. lanes 7 and 8 with lanes 11 and 12). This resembles the pattern obtained using high levels of Jurkat extract alone (lanes 1,2$)$. In contrast, transcription of the $\alpha$-globin internal control remains constant under these conditions indicating that components in the Jurkat extract repress the enhancerless $V_{\alpha}$ promoter template in a selective rather than non-specific manner. These results are quantitated and graphed in Figure 3B.

\section{DNA topology is critical for distal enhancer function in vitro}

We then assessed the effect of DNA topology on enhancer-dependent gene expression in vitro by measuring the transcriptional efficiency of $\mathrm{TCR} \alpha$ gene plasmids that were either supercoiled or completely relaxed by topoisomerase I. As shown in Figure 4A, supercoiled TCR $\alpha$ plasmids are transcribed in an enhancer-dependent manner in Jurkat extracts (lanes $1,3,5,6)$. However, if enhancer-containing TCR $\alpha$ plasmids are relaxed by to-
A

B
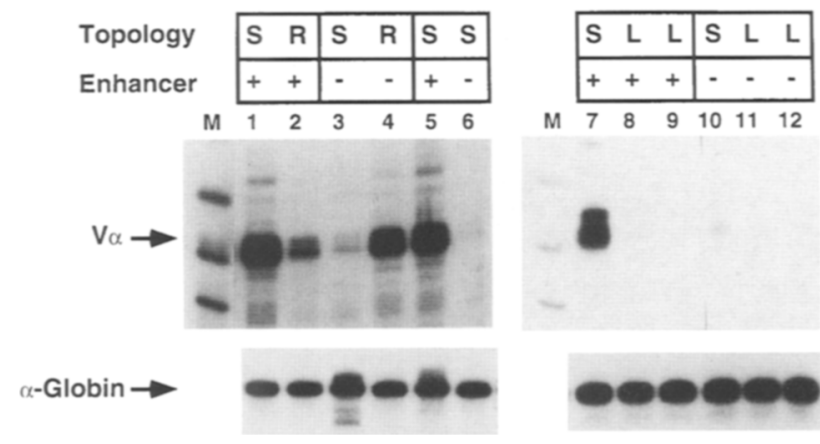

Figure 4. Enhancer-dependent $\mathrm{TCR} \alpha$ gene transcription requires a specific DNA topology. (A) Distal enhancer-regulated transcription of supercoiled and relaxed TCR $\alpha$ genes in vitro. Supercoiled (S) or topoisomerase I relaxed (R) TCR $\alpha$ plasmids, pTCR1700TCRen and pTCR1700, were each incubated with Jurkat transcription extracts at $10 \mathrm{\mu g} / \mathrm{ml}$ under the conditions described in Materials and Methods. The following DNA templates were examined: Supercoiled TCR $\alpha+$ enhancer (lanes 1,5); relaxed TCR $\alpha+$ enhancer (lane 2); supercoiled TCR $\alpha-$ enhancer (lanes 3,6); relaxed TCR $\alpha$ - enhancer (lane 4). In addition, $25 \mathrm{ng}(0.5 \mu \mathrm{g} / \mathrm{ml})$ of a human $\alpha$-globin plasmid was included in each reaction as an internal transcription and recovery control. $(B)$ Distal enhancer-regulated transcription of linearized TCR $\alpha$ genes in vitro. Supercoiled (S) or restriction enzyme-linearized (L) TCR $\alpha$ plasmids, pTCR1700TCRen and pTCR1700, were incubated with Jurkat T-cell extracts at 10 $\mathrm{\mu g} / \mathrm{ml}$ under the conditions described above. pTCR1700TCRen and pTCR 1700 were each linearized by digestion with HindIII or SmaI, deproteinized, and ethanol precipitated prior to transcription. The following DNA templates were analyzed: TCR $\alpha$ + enhancer, supercoiled (lane 1), linearized with HindIII (lane 2) or SmaI (lane 3); TCR $\alpha$ - enhancer, supercoiled (lane 4), linearized with HindIII (lane 5) or SmaI (lane 6). (Bottom) $25 \mathrm{ng}$ $(0.5 \mu \mathrm{g} / \mathrm{ml})$ of a human $\alpha$-globin plasmid was included in each reaction as an internal control. 
poisomerase I, transcription is significantly decreased (lane 2). In contrast, the opposite results are observed for TCR $\alpha$ genes deleted of the enhancer. Relaxation of these plasmids increases their transcriptional efficiency markedly (lane 4). Interestingly, as shown in Figure 4B, when $\mathrm{TCR} \alpha$ plasmids are linearized by digestion with either HindIII or SmaI, transcription is inactivated in the presence (lanes 8,9) and absence (lanes 11,12) of the enhancer, whereas when supercoiled, only enhancerless templates are inactive (cf. lanes 7 and 10). Taken together, these data indicate that in Jurkat $T$ cell extracts a supercoiled DNA structure is required for efficient $\mathrm{TCR} \alpha$ gene transcription in the presence of the enhancer and for efficient repression of the $V_{\alpha}$ promoter when the enhancer is deleted. In addition, the TCR $\alpha$ enhancer regulates positively the $V_{\alpha}$ promoter when supercoiled but negatively regulates the promoter when the gene is relaxed. The observation that linearized templates are inactivated in an enhancer-independent manner suggests that this occurs by a mechanism distinct from that which operates through changes in DNA superhelicity.

$H M G I / Y$ selectively represses the $\mathrm{V}_{\alpha}$ promoter in $a$ topologically sensitive manner and is relieved by the distal TCR $\alpha$ enhancer

The observation that TCR $\alpha$ genes are inactivated selectively in the absence of the enhancer in Jurkat extracts suggested that diffusible repressors may be present in $\mathrm{T}$-cell protein preparations. In addition, enhancer-dependent transcription of the TCR $\alpha$ genes in Jurkat extract is modulated significantly by the topology of the input DNA. These results supported the idea that the interaction of the putative repressor with the $V_{\alpha}$ promoter is sensitive to changes in the topological structure of the DNA template. This led us to focus our attention on architectural proteins that are known to bind DNA in a structure-sensitive manner. These include proteins such as LEF-1, YY-1, histone H1, YB-1, HMG I/Y, and HMG1. We tested several of these factors in transcriptional complementation assays to examine their potential role in enhancer-dependent $V_{\alpha}$ promoter regulation. In this analysis, concentrations of Jurkat extracts that contain low levels of repressor activity and efficiently transcribe $\mathrm{TCR} \alpha$ genes in an enhancer-independent manner (see Fig. 2A/ were used to determine whether specific purified proteins could repress selectively the $V_{\alpha}$ promoter and restore enhancer-dependent transcription.

The mammalian HMG $\mathrm{I} / \mathrm{Y}$ protein family is composed of three members: 11.9-kD HMG I, 10.6-kD HMG Y, and $12-\mathrm{kD}$ HMG I-C. The HMG I and Y proteins are identical in sequence except for an 11-amino-acid internal deletion in the latter and are produced by alternative splicing. HMG I/Y binding markedly alters DNA conformation by introducing bends, supercoils, and other distortions in the template. These proteins also recognize both AT-rich sequences and non-B DNA structures such as cruciforms (for review, see Bustin and Reeves 1996). Therefore, we tested initially recombinant HMG I in our complementation assays. As shown in Figure 5A, Jurkat extracts at a concentration of $7 \mu \mathrm{g} / \mathrm{ml}$ transcribe supercoiled TCR $\alpha$ genes in the presence or absence of the enhancer (lanes 1,2). However, when these reactions are complemented with increasing amounts of recombinant HMG I, transcription is repressed selectively on the enhancerless template by 12 -fold (cf. lanes 2, 4, and 6), but unaffected when the enhancer is present (cf. lanes 1, 3, and 5). In contrast, when HMG I is used to complement HeLa extracts, TCR $\alpha$ gene expression is stimulated twofold with or without the enhancer (Fig. 5B, cf. lanes 7 and 8 with lanes 11 and 12). These results indicate that HMG $\mathrm{I} / \mathrm{Y}$ functions quite differently on the TCR $\alpha$ gene in a Jurkat or HeLa transcription environment. In Jurkat extracts, HMG I/Y has a critical role in mediating repression of supercoiled enhancerless $V_{\alpha}$ promoters that can be relieved effectively in an enhancer-dependent manner. In HeLa extracts, HMG I/Y activates TCR $\alpha$ transcription by an enhancer-independent mechanism. Thus, HMG I/Y is not behaving as a general repressor as it would be expected to inactivate TCR $\alpha$ transcription in both Jurkat and HeLa extracts, but only be relieved in Jurkat extracts that can form an active TCR $\alpha$ enhancer with $\mathrm{T}$ cell proteins. Instead, it is functioning as a repressor of the $V_{\alpha}$ promoter only in combination with other factors present in Jurkat but not HeLa extracts and, therefore, is a critical component of a potentially larger repressor complex. In addition, incubation of HMG I/Yspecific antibodies with Jurkat extracts abrogates enhancer-dependent TCR $\alpha$ transcription by preventing repression of enhancerless $V_{\alpha}$ promoters (data not shown). This indicates that HMG $I / Y$ is the actual protein that functions in Jurkat cells rather than simply mimicking the activity of another factor.

A prediction of our results demonstrating a strong dependence of enhancer-regulation on DNA topology (see Fig. 4A) is that the HMG I/Y-containing repressor complex should inactivate supercoiled but not relaxed $V_{\alpha}$ promoters in the absence of the enhancer. We tested this prediction by examining the ability of HMG I to restore repression to either supercoiled or relaxed TCR $\alpha$ gene plasmids in a Jurkat extract complementation assay. As shown in Figure 5C, transcription of enhancerless TCR $\alpha$ genes with Jurkat extracts in repressor excess $(10 \mu \mathrm{g} / \mathrm{ml})$ inactivates expression of supercoiled templates (lane 13), but not when relaxed by topoisomerase I (lane 14). Reactions containing lower concentrations of Jurkat extract with limiting repressor $(7 \mu \mathrm{g} / \mathrm{ml})$ efficiently transcribe both supercoiled and relaxed templates (lanes $15,16)$. When these reactions are complemented with HMG I, the supercoiled TCR $\alpha$ genes are repressed substantially (cf. lane 15 with lane 17), whereas relaxed genes are unaffected (cf. lane 16 with lane 18 and lane 14 with lane 19l. This indicates that HMG I/Y-containing repressor complex functions only when $V_{\alpha}$ promoters are in a topologically sensitive structure that is presumably abolished in relaxed plasmids.

The effect of other architectural proteins, histone $\mathrm{H} 1$, YY1, and HMG 1, on enhancer-regulated TCR $\alpha$ gene expression was examined by complementation analysis using Jurkat extracts at a concentration containing limit- 
A

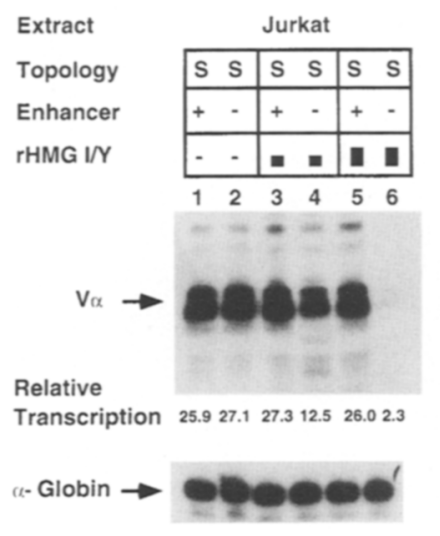

B

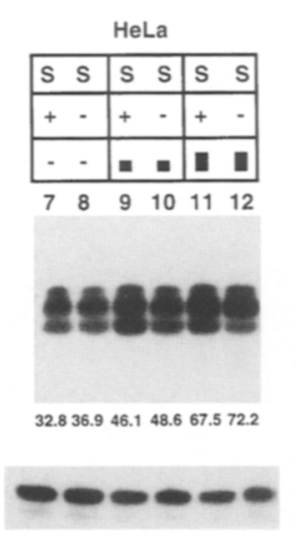

C

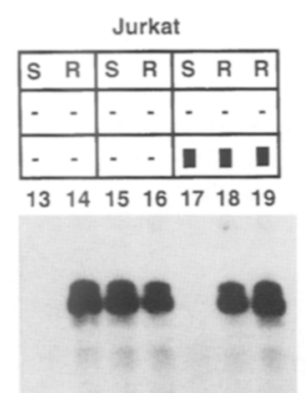

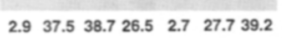

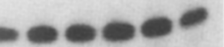

Figure 5. The architectural protein HMG $\mathrm{I} / \mathrm{Y}$ can restore TCR $\alpha$ enhancer-dependent transcription by mediating $V_{\alpha}$ promoter repression. (A) In vitro transcription of supercoiled TCR $\alpha$ genes using Jurkat extracts complemented with recombinant HMG I/Y. Supercoiled TCR $\alpha$ plasmids pTCR1700TCRen (lanes 1,3,5) and pTCR1700 (lanes 2,4,6) were each incubated with $200 \mathrm{ng}$ (lanes 3,4) or $400 \mathrm{ng}$ (lanes 5,6) of fast protein liquid chromotography (FPLC)-purified, recombinant HMG I/Y. Reactions were performed with $7 \mu \mathrm{g} / \mathrm{ml}$ of $\mathrm{Ju}$ rkat $\mathrm{T}$-cell extract that contains limiting concentrations of repressor activity (see Fig. 2A) and efficiently transcribe TCR $\alpha$ genes in the presence or absence of the enhancer (lanes 1,2). Relative transcription in arbitrary units is listed below each lane. (Bottom) $25 \mathrm{ng}(0.5 \mu \mathrm{g} / \mathrm{ml})$ of a human $\alpha$-globin plasmid was included in each reaction as an internal control for transcription and recovery. $(B)$ In vitro transcription of supercoiled TCR $\alpha$ genes using HeLa extracts complemented with recombinant HMG I/Y. Supercoiled TCR $\alpha$ plasmids, pTCR1700TCRen (lanes 7,9,11) and pTCR1700 (lanes 8,10,12), were each incubated with $200 \mathrm{ng}$ (lanes 9,10) or $400 \mathrm{ng}$ (lanes 11,12) of FPLC-purified rHMG I/Y. Transcriptions were performed with $10 \mu \mathrm{g} / \mathrm{ml}$ of HeLa cell extracts (lanes 7,8). Relative transcription in arbitrary units is listed below each lane. (Bottom) $25 \mathrm{ng}(0.5 \mu \mathrm{gg} / \mathrm{ml})$ of a human $\alpha$-globin plasmid was included in each reaction as an internal control. $(C)$ In vitro transcription of relaxed TCR $\alpha$ genes using Jurkat extracts complemented with recombinant HMG I/Y. Topoisomerase I-relaxed (lanes 14,16,18,19) and supercoiled (lanes $13,15,17$ ) TCR $\alpha$ plasmids pTCR1700 were each incubated with either buffer alone (lanes 13-16) or 400 ng of FPLC-purified rHMG I/Y (lanes 17-19). Transcriptions were performed using either $10 \mu \mathrm{g} / \mathrm{ml}$ (lanes 13,14,19) or $7 \mu \mathrm{g} / \mathrm{ml}$ (lanes 15-18) of Jurkat T-cell extracts. Relative transcription in arbitrary units is listed below each lane. (Bottom) $25 \mathrm{ng}(0.5 \mu \mathrm{g} / \mathrm{ml}$ ) of a human $\alpha$-globin plasmid was included in each reaction as an internal control.

ing levels of endogenous repressor as in Figure 5. As shown in Figure 6A, addition of increasing amounts of purified histone $\mathrm{H} 1$ to Jurkat extracts resulted in a progressive repression of transcription of supercoiled TCR $\alpha$ gene plasmids in the presence or absence of the enhancer (cf. lanes 1 and 2 with lanes 3-6). Apparently this is attributable to nonspecific effects as the $\alpha$-globin internal control is similarly inactivated in these reactions. Complementation of Jurkat extracts with either recombinant YY1 (Fig. 6B) or HMG 1 (Fig. 6C) had negligible effects on supercoiled TCR $\alpha$ gene transcription with or without the enhancer. This does not necessarily exclude a role for these proteins in enhancer regulation, but their function appears to be distinct from that of HMG I/Y in this complementation assay in which other components of the repressor complex are not limiting. In conclusion, these results demonstrate a specific role for an HMG $\mathrm{I} / \mathrm{Y}$-containing complex as a topologically sensitive transcriptional repressor of the $V_{\alpha}$ promoter whose effects can be abrogated at long-range by an active TCR $\alpha$ enhancer.

\section{Discussion}

We describe a soluble in vitro transcription system derived from Jurkat $T$ cells in which expression of the cloned TCR $\alpha$ gene is completely dependent on its distal $3^{\prime} \alpha$ enhancer. We make four important observations: (1) distal enhancers act by promoter derepression when placed at a considerable distance $(>2 \mathrm{~kb})$ from the initiation site; (2) natural enhancers act by increasing the number of active templates rather than the rate of tran- scription; (3) the enhancer-responsive repressor complex contains $\mathrm{T}$-cell factors and HMG I/Y as a critical component; and (4) DNA topology plays a significant role in modulating the activity and enhancer dependence of the repressor complex. A similar system has also been developed for enhancer-dependent transcription of cloned chick $\beta$-globin genes using protein extracts obtained from primary embryonic chick red blood cells (M.C. Barton, N. Madani, and B.M. Emerson, in prep.). Thus, in vivo patterns of regulation are achieved using two different developmentally controlled genes by tissue-specific cellular enhancers acting at distances of $\sim 2.5 \mathrm{~kb}$. Previous RNA Pol II in vitro transcription systems have been described that demonstrate enhancer-dependent expression of cloned genes (Sergeant et al. 1984; Wildeman et al. 1984; Schöler and Gruss 1985; Flanagan and Crabtree 1992). However, these studies examined DNA templates in which viral or cellular enhancers were placed in very close proximity to the promoter. The goal of our work was to reproduce enhancer-dependent transcriptional regulation at a considerable distance from the promoter as this may be mechanistically distinct from enhancers that function as upstream promoter elements. In this regard, two in vitro studies demonstrated that GAL4VP16 bound to multiple sites could activate transcription of model genes at a distance of $>1.0 \mathrm{~kb}$ using either naked DNA in crude HeLa extracts (Carey et al. 1990) or histone H1-containing nucleosome-reconstituted templates (Laybourn and Kadonaga 1992). In another interesting experiment, a yeast RNA Pol I enhancer within the ribosomal gene spacer was shown to activate transcription from its cognate promoter in a yeast cell-free 


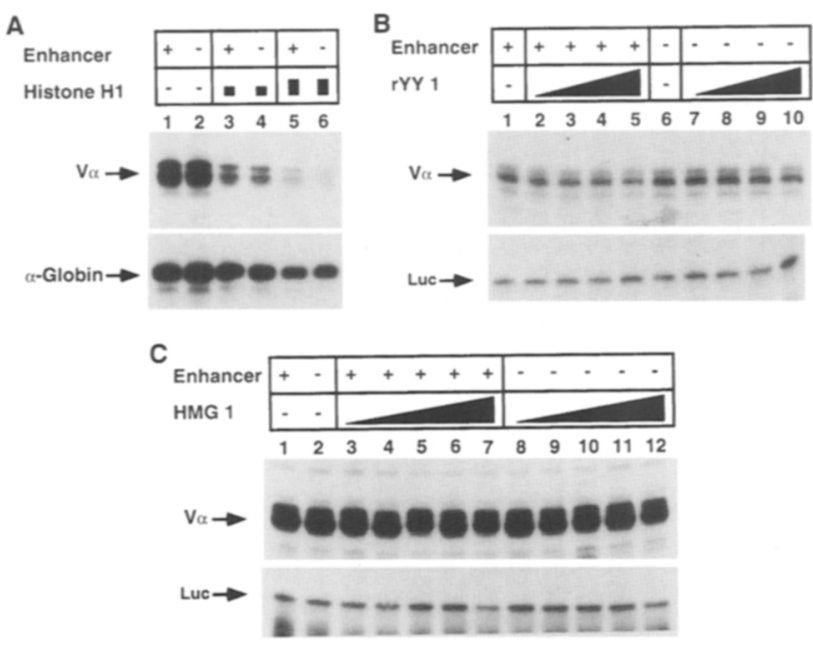

Figure 6. Effect of other architectural proteins on enhancerdependent TCR $\alpha$ transcription. $(A)$ In vitro transcription of TCR $\alpha$ genes using Jurkat extracts complemented with histone H1. Supercoiled TCR $\alpha$ plasmids pTCR1700TCRen (lanes 1,3,5) and pTCR 1700 (lanes 2,4,6), were each incubated with $150 \mathrm{ng}$ (lanes 3,4) or $300 \mathrm{ng}$ (lanes 5,6) of purified Drosophila histone $\mathrm{H} 1$. Transcriptions were performed using $7 \mu \mathrm{g} / \mathrm{ml}$ of Jurkat $\mathrm{T}$ cell extract in which repressor activity is limiting (lanes 1,2 ). (Bottom) $25 \mathrm{ng}(0.5 \mu \mathrm{g} / \mathrm{ml})$ of a human $\alpha$-globin plasmid was included in each reaction as an internal control for transcription and recovery. (B) Complementation of Jurkat extract with recombinant YY1. Supercoiled TCR $\alpha$ plasmids pTCR1700TCRen (lanes 1-5) and pTCR1700 (lanes 6-10) were each incubated with $50 \mathrm{ng}$ (lanes 2,7), $100 \mathrm{ng}$ (lanes 3,8), $150 \mathrm{ng}$ (lanes 4,9), or $200 \mathrm{ng}$ (lanes 5,10) of purified YY1. Transcriptions were performed using $7 \mu \mathrm{g} / \mathrm{ml}$ of Jurkat T-cell extract containing limiting amounts of repressor activity (lanes 1,6). (Bottom) $25 \mathrm{ng}(0.5$ $\mu \mathrm{g} / \mathrm{ml}$ ) of an adenovirus major late promoter/luciferase (Luc) plasmid was included in each reaction as an internal control. $(C)$ Complementation of Jurkat extract with purified HMG I. Supercoiled TCR $\alpha$ plasmids pTCR1700TCRen (lanes 1,3-7) and pTCR 700 (lanes 2,8-12) were each incubated with $50 \mathrm{ng}$ (lanes 3,8), $100 \mathrm{ng}$ (lanes 4,9), $150 \mathrm{ng}$ (lanes 5,10), $200 \mathrm{ng}$ (lanes 6,11), or $400 \mathrm{ng}$ (lanes 7,12) of calf thymus HMG I. Transcriptions were performed using $7 \mu \mathrm{g} / \mathrm{ml}$ of Jurkat T-cell extracts in which repressor activity is limiting (lanes 1,2). (Bottom) $25 \mathrm{ng}(0.5 \mu \mathrm{g}$ / $\mathrm{ml}$ ) of Luc plasmid was included in each reaction as an internal control.

extract at a distance of $\sim 700$ bp (Schultz et al. 1993). In most Pol I and Pol II in vitro systems, the proximal and distal enhancer effects observed showed no dependence on DNA topology as they were identical on circular or linear DNA templates when examined. In the Jurkat $T$ cell transcription system that we describe long-range TCR $\alpha$ enhancer function is completely dependent on DNA topology and a repressor complex with HMG I/Y as a critical component. It is important to note that in this in vitro system, the exact role of chromatin structure in enhancer regulation is difficult to assess as crude transcription extracts contain nucleosomal components that may be assembled onto plasmids and required to generate a functional template.
The role of architectural protein-induced DNA topologies in gene expression has been documented extensively at several levels. For example, the formation of higher order nucleoprotein structures that are required for processes such as site-specific recombination and promoterenhancer function have been shown to involve the initial interaction of architectural factors. These are specific or nonspecific DNA-binding proteins that induce conformational changes in the DNA, which allow neighboring nonadjacent proteins to form direct contacts with each other to generate a functional higher order complex. In particular, eukaryotic proteins in the HMG (high mobility group) family, LEF-1, sex-determining region $\mathrm{Y}$ (SRY), upstream binding factor (UBF), HMG-1, HMG-2, HMG I/Y, and analogous prokaryotic proteins IHF (integration host factor) and $\mathrm{HU}$, have been shown to bend or distort DNA and facilitate interactions between neighboring factors (for review, see Grosschedl 1995; Bustin and Reeves 1996). For example, HMG I/Y forms complexes with both NF- $\mathrm{BB}$ and ATF-2 and stimulates the binding of these factors to virus-inducible regulatory regions of the human interferon- $\beta$ gene. HMG I/Y binds to these regions through contacts in the minor groove, whereas $\mathrm{NF}_{-\kappa \mathrm{B}}$ and ATF-2 interact with the same sequences in the major groove (Thanos and Maniatis 1995). These and other studies illustrate the importance of protein-induced localized DNA distortion in the regulation of genetic processes such as recombination and transcription. However, in most cases, the effects of DNA structural changes occurred over relatively short distances of -100 to several hundred base pairs. To address long-range regulation between distal sites that are separated by kilobases, other aspects of DNA topology should be considered.

In the nucleus, DNA is believed to be organized into independent loops comprised of topologically closed domains. These closed domains, like supercoiled DNA, are structurally dynamic and can adopt many different configurations depending on the total bending and twisting deformations (for review, see Ner et al. 1994; Yang et al. 1995). These configurations can alter dramatically the structure of the entire DNA molecule or may exist at discrete sequences. Localized non-B form conformations include cruciforms, hairpin structures, four-way junctions, untwisted regions, and crossovers generated by supercoiling. Specific proteins, such as HU, HMG-1, HMG2, and HMG-I/Y may either induce or stabilize these irregular DNA structures and act as "chaperones" in the formation of particular DNA topologies that are active for specific nuclear processes (Ner et al. 1994). In addition, other regulatory proteins may only recognize irregular DNA structures and be unable to bind to B form duplex DNA. Thus, another level of gene regulation is imposed by the existence of a class of proteins binding unusual DNA structures that are generated by chaperones or architectural proteins, which stabilize a preferred template configuration. If the DNA is unable to exist in various topologies, then this hierarchy of control presumably would be lost. The importance of unusual DNA structures in transcriptional regulation has been well 
documented (Kohwi and Kohwi-Shigematsu 1991; Glucksmann et al. 1992). Specific examples in natural eukaryotic genes include the demonstration that a transacting protein, fuse-binding protein (FBP) regulates c-myc promoter activity by interacting with a far upstream element FUSE that exists in a partially unwound configuration in negatively supercoiled DNA /Duncan et al. 1994) and the transcription factor YB-1 regulates class II major histocompatibility complex (MHC) genes by binding to single-stranded regions within the DRA promoter (MacDonald et al. 1995).

On the basis of these observations, it is reasonable to predict that promoters and distal enhancers within topologically closed DNA domains can communicate through a particular structural configuration that occurs across kilobases that can be stabilized by proteins like HMG I/Y or other architectural factors. We speculate that the function of long-range transcriptional enhancers is to modulate the topology of the gene or genetic locus that it is associated with and to regulate the maintenance of localized non-B DNA structures such as underwound sequences, hairpins, cruciforms, in transcriptional control regions. Thereby enhancers could determine the interaction pattern of proteins that recognize these unusual DNA conformations such as the TCR $V_{\alpha}$ promoter repressors. In this scenario, the bipartite nature of the repressor complex can be understood by presuming that the binding of HMG I/Y to supercoiled $V_{\alpha}$ promoters creates a template topology that is now responsive to the $\mathrm{T}$ cell repressors. Once this complex is formed, promoter inactivation occurs in the absence of the enhancer. When the enhancer is present, the higher order complex within this element, composed of LEF-1 and other T-cell proteins, may offset the topology generated by HMG I/Y at a distance and allow derepression of the promoter. As predicted and demonstrated in our experiments, the initial DNA topology, supercoiled or relaxed, plays a significant role in determining the ability of architectural protein-induced complexes to form and regulate transcriptional activity.

Thus, enhancers may have evolved to provide a more refined level of topological control than is established initially within a closed DNA domain by the action of topoisomerases. This suggests that association with an enhancer renders promoter function highly dependent on DNA topology, which creates another level of transcriptional control and potentially links gene activity to the overall conformation or torsional strain of the chromosomal domain in which it resides. This proposed mechanism of enhancer function is distinct from one in which distal enhancers are brought into close proximity with promoters and activate gene expression by increasing the local concentration of transcription factors. In fact, Rippe et al. (1995) concluded that for distances between 1 and $5 \mathrm{~kb}$, DNA looping does not increase significantly the equilibrium concentration of individual activator proteins bound to enhancer sites above the free solution concentrations that might be expected. It seems unlikely that distal regulatory elements would have evolved for the sole purpose of activating promoters when upstream sequences adjacent to the initiation complex achieve this with great efficiency. It is more logical to invoke a distinct role for enhancers that, perhaps, upstream promoter elements do not perform. In our case, the TCR $\alpha$ enhancer appears to act as a mediator that responds to changes in DNA topology by regulating the activity of the $V_{\alpha}$ promoter accordingly. This requires the existence of repressor proteins that, we speculate, associate with topologically distinct regions of DNA.

Whether long-range TCR $\alpha$ promoter-enhancer communication involves DNA looping to bring distal sequences into close proximity (Ptashne 1986; Dunaway and Droge 1989), protein tracking along DNA (Herendeen et al. 1992), or another process is unknown at present. We favor a mechanism in which DNA topology strongly influences interaction between the TCR $\alpha$ enhancer and $V_{\alpha}$ promoter that may involve direct protein contact or indirect communication from the propagation of a structural change through the intervening sequence. The latter process has been demonstrated recently to be responsible for the long-range activation of the prokaryotic leu500 promoter by an upstream promoter (Wu et al. 1995). Experiments to address this issue using the TCR $\alpha$ gene in our in vitro system are now in progress. We hope that this system will provide a valuable approach to elucidate the molecular events that determine critical longrange interactions within and between chromosomal domains.

\section{Materials and methods}

Plasmid preparation

Plasmids pTCR1700TCRen and pTCR 1700 were prepared from Escherichia coli $\mathrm{DH} 5 \alpha$ cells by the TritonX-100 lysis method and further purified by sedimentation through ethidium bromide-CsCl density gradients.

\section{Preparation of protein extracts}

Jurkat $\mathrm{T}$ cells were grown in suspension culture at $37^{\circ} \mathrm{C}$ to a density of $0.5 \times 10^{6}$ to $0.6 \times 10^{6}$ cells $/ \mathrm{ml}$ in Click's medium supplemented with $10 \%$ FBS. All further procedures were carried out at $4^{\circ} \mathrm{C}$. Cells were washed twice with cold PBS and gently resuspended in 1.5 times the packed cell volume in modified hypotonic buffer [20 mM HEPES (pH 7.9), $10 \mathrm{mM} \mathrm{NaCl}, 1.5$ $\mathrm{mm} \mathrm{MgCl}_{2}, 2.0 \mathrm{~mm}$ DTT, $0.2 \mathrm{~mm}$ EDTA, $15 \%$ glycerol] supplemented with protease inhibitors $(2 \mu \mathrm{g} / \mathrm{ml}$ of aprotinin, $1 \mu \mathrm{M}$ pepstatin, $100 \mu \mathrm{M}$ leupeptin, $1 \mathrm{~mm}$ benzamidine, and $0.2 \mathrm{~mm}$ PMSF). Cells were lysed by Dounce homogenization with nine strokes of pestle A. Chromatin was extracted from lysed cells by addition of $5 \mathrm{M} \mathrm{NaCl}$ to a final concentration of $0.26 \mathrm{M}$ with continuous swirling. Nuclear protein extraction was continued with stirring for another $30 \mathrm{~min}$ at $4^{\circ} \mathrm{C}$. The mixture was then centrifuged to pellet the extracted chromatin. Clear lysate was removed carefully and dialysed for $6 \mathrm{hr}$ against $20 \mathrm{mM}$ HEPES (pH 7.9), $50 \mathrm{~mm} \mathrm{KCl}, 1.0 \mathrm{~mm}$ DTT, $0.2 \mathrm{~mm}$ EDTA, and $20 \%$ glycerol with one change of buffer after $3 \mathrm{hr}$. The dialysate was centrifuged briefly to remove insoluble debris. The supernatant was aliquoted and stored at $-100^{\circ} \mathrm{C}$. Protein concentrations were typically between 25 and $40 \mathrm{mg} / \mathrm{ml}$. Extracts from HeLa cells were prepared identically. 


\section{Preparation of proteins}

Recombinant HMG I/Y protein from pET7C clone (a gift from Dr. Ray Reeves) was expressed and purified by established procedures (Nissen et al. 1991). Protein concentration of the FPLCpurified HMG I/Y was measured spectrophotometrically using $\epsilon 220=74,000$ liters $/$ mole per $\mathrm{cm}$ (Nissen et al. 1991). Recombinant YY1 was purified from clone pHis-YY1 (a gift from Dr. Thomas Shenk) according to established procedures (Shi et al. 1991). Both proteins were analyzed by SDS-PAGE for integrity and purity. Drosophila histone $\mathrm{HI}$ and calf thymus HMG 1 were kind gifts of Drs. Phil Sheridan (Salk Institue, La Jolla, California) and Ray Reeves, respectively.

\section{In vitro transcription}

Reactions containing $0.5 \mu \mathrm{g}$ of TCR $\alpha$ DNA and $25 \mathrm{ng}$ of $\alpha$-globin DNA were incubated with 200-250 $\mu$ g of protein extract (except where specified) in a buffer containing $20 \mathrm{mM}$ HEPES ( $\mathrm{pH} 7.9$ ), $70 \mathrm{~mm} \mathrm{KCl}, 5 \mathrm{~mm} \mathrm{MgCl}_{2}, 10 \%$ glycerol, $1 \mathrm{~mm}$ DTT, and $0.6 \mathrm{~mm}$ rNTPs in a final volume of $50 \mu \mathrm{l}$ at $30^{\circ} \mathrm{C}$ for $30-60 \mathrm{~min}$ unless otherwise noted. After transcription, RNA was purified by proteinase $\mathrm{K}$ digestion, phenol-chloroform extraction, and ethanol precipitation. Samples were then divided in half and processed separately by AMV reverse transcriptase-mediated primer extension using either a $V_{\alpha} 11.1$ - or an $\alpha$-globin-specific ${ }^{32} \mathrm{P}$-labeled oligonucleotide primer before electrophoretic analysis on an $8 \%$ PAGE $/ 8 \mathrm{M}$ urea/TBE gel. ImageQuant (Molecular Dynamics) was used to quantify the relative amounts of the transcription reaction products after autoradiography. Template utilization in this in vitro transcription reaction was between $1 \%$ and $2 \%$.

Supercoiled DNA templates were relaxed using wheat germ topoisomerase I (Epicentre Technologies) according to the vendor's recommendations. Complete relaxation was confirmed by agarose gel electrophoresis. Fully relaxed plasmids were purified by phenol- $\mathrm{CHCl}_{3}$ extraction and ethanol precipitation before use as templates in the in vitro transcription reactions. Supercoiled DNA templates were linearized using HindIII or SmaI restriction enzyme. Both of these enzymes cleave at a unique site in the TCR $\alpha$ plasmid. HindIII cuts $1.6 \mathrm{~kb}$ upstream and $S m a$ I cuts 138 bp downstream of the $V_{\alpha}$ promoter transcription start site. Complete DNA linearization was confirmed by agarose gel electrophoresis. Fully relaxed plasmids were purified by phenol- $\mathrm{CHCl}_{3}$ extraction and ethanol precipitation before use as templates in the in vitro transcription reactions.

Complementation experiments with HMG I/Y involved preincubation of supercoiled or relaxed DNA templates with FPLC-purified recombinant protein at $30^{\circ} \mathrm{C}$ in $20 \mathrm{mM}$ HEPES (pH 7.9), $5 \mathrm{~mm} \mathrm{MgCl}_{2}, 50 \mathrm{mM} \mathrm{KCl}, 5 \mathrm{~mm}$ DTT, and $200 \mu \mathrm{g} / \mathrm{ml}$ of BSA in $10 \mu \mathrm{l}$ of reaction volume followed by transcription with Jurkat or HeLa protein extracts as described above.

\section{Site-directed mutagenesis}

Site-directed mutagenesis was performed at the LEF-1-binding site within plasmids containing the TCR $\alpha$ enhancer (pTCR1700TCRen) using the Chameleon Double-Stranded, Site-Directed Mutagenesis Kit from Stratagene, CA. An oligonucleotide having an SmaI recognition sequence $\left(5^{\prime}-\mathrm{GG}\right.$ GACTCTAGAGGATCCCCTGGAGCTTGGCAGATTTTCA) was used as a selection primer and (5'-GGCAAACAGGTCCCCCATAGAAGCTCTCCCGCAG) was used as a mutagenic primer. Mutational analysis of the resulting plasmid, pTCR1700TCRmten, was confirmed by dideoxy sequencing.

\section{Acknowledgments}

We thank Dr. Katherine Jones for a critical reading of the manuscript and Dr. Michelle Barton and Jennifer Armstrong for many helpful discussions and suggestions during the course of this work. We are also indebted to Drs. Astar Winoto, Phil Sheridan, and Ray Reeves for their gifts of TCR $\alpha$ plasmids, Drosophila histone $\mathrm{H} 1$, and recombinant HMG I/Y DNA, respectively, and to Ro Sabnis for expertly performing site-directed mutagenesis. R.B. thanks Rekha and Isha for the constant support during the course of this work. This project was funded by a grant to B.M.E. from the National Institutes of Health (POI CA 54418) and R.B. was supported by a postdoctoral fellowship from the Arthritis Foundation.

The publication costs of this article were defrayed in part by payment of page charges. This article must therefore be hereby marked "advertisement" in accordance with 18 USC section 1734 solely to indicate this fact.

\section{References}

Barton, M.C. and B.M. Emerson. 1994. Regulated expression of the $\beta$-globin gene locus in synthetic nuclei. Genes \& Dev. 8: $2453-2465$.

Bustin, M. and R. Reeves. 1996. High-mobility-group chromosomal proteins: Architectural components that facilitate chromatin function. Prog. Nucleic Acid Res. Mol. Biol. 54: 35-100.

Carey, M., J. Leatherwood, and M. Ptashne. 1990. A potent GAL4 derivative activates transcription at a distance in vitro. Science 247: 710-712.

Capone, M., F. Watrin, C. Fernex, B. Horvat, B. Krippl, L. Wu, R. Scollay, and P. Ferrier. 1993. TCR beta and TCR alpha gene enhancers confer tissue- and stage-specificity on V(D)J recombination events. EMBO J. 12: 4335-4346.

Dunaway, M. and P. Droge. 1989. Transactivation of the Xenopus rRNA gene promoter by its enhancer. Nature 341: 657659.

Duncan, R., L. Bazar, G. Michelotti, T. Tomonaga, H. Krutzsch, M. Avigan, and D. Levens. 1994. A sequence-specific, singlestrand binding protein activates the far upstream element of c-myc and defines a new DNA-binding motif. Genes \& Dev. 8: $465-480$.

Flanagan, W.M. and G.R. Crabtree. 1992. In vitro transcription faithfully reflecting $\mathrm{T}$ cell activation requirements. J. Biol. Chem. 267: 399-406.

Flavo, J.V., D. Thanos, and T. Maniatis. 1995. Reversal of intrisnic DNA bends in the IFN $\beta$ gene enhancer by transcription factors and the architectural protein HMG I/Y). Cell 83: $1101-1111$.

Giese, K., J. Cox, and R. Grosschedl. 1992. The HMG domain of lymphoid enhancer factor 1 bends DNA and facilitates assembly of functional nucleoprotein structures. Cell 69: 185195.

Giese, K., C. Kingsley, J.R. Kirschner, and R. Grosschedl. 1995. Assembly and function of a TCR $\alpha$ enhancer complex is dependent on LEF-1-induced DNA bending and multiple protein-protein interactions. Genes \& Dev. 9: 995-1008.

Glucksmann, M.A., P. Markiewicz, C. Malone, and L.B. Rothman-Denes. 1992. Specific sequences and a hairpin structure in the template strand are required for N4 virion RNA polymerase promoter recognition. Cell 70: 491-500.

Grosschedl, R. 1995. Higher-order nucleoprotein complexes in transcription: Analogies with site-specific recombination. Curr. Opin. Cell Biol. 7: 362-370.

Hawley, D.K. and R.G. Roeder. 1987. Functional steps in initia- 
tion and reinitiation from the major late promoter in a $\mathrm{HeLa}$ nuclear extract. J. Biol. Chem. 262: 3452-3461.

Herendeen, D.R., G.A. Kassavetis, and E.P. Geiduschek. 1992. A transcriptional enhancer whose function imposes a requirement that proteins track along DNA. Science 256: 1298-1303.

Kingsley, C. and A. Winoto. 1992. Cloning of GT box-binding proteins: A novel $\mathrm{Spl}$ multigene family regulating $\mathrm{T}$ cell receptor gene expression. Mol. Cell Biol. 12: 4251-4261.

Kohwi, Y. and T. Kohwi-Shigematsu. 1991. Altered gene expression correlates with DNA structure. Genes \& Dev. 5: 25472554.

Laybourn, P.J. and J.T. Kadonaga. 1992. Threshold phenomena and long-distance activation of transcription by RNA polymerase II. Science 257: 1682-1685.

Leiden, J.M. 1993. Transcriptional regulation of T cell receptor genes. Annu. Rev. Immunol. 11: 539-570.

MacDonald, G.H., Y. Itoh-Lindstrom, and J.P.-Y. Ting. 1995. The transcriptional regulatory protein, YB-1, promotes single-stranded regions in the DRA promoter. J. Biol. Chem. 270: 3527-3553.

Majumder, S., M. Miranda, and M.L. DePamphilis. 1993. Analysis of gene expression in mouse preimplantation embryos demonstrates that the primary role of enhancers is to relieve repression of promoters. EMBO I. 12: 1131-1140.

Ner, S.S., A.A. Travers, and M.E. Churchill. 1994. Harnessing the writhe: A role for DNA chaperones in nucleoproteincomplex formation. Trends Biol. Sci. 19: 185-187.

Nissen, M.S., T.A. Langan, and R.Reeves. 1991. Phosphorylation by cdc2 kinase modulates DNA binding activity of high mobility group I nonhistone chromatin protein. I. Biol. Chem. 266: 19945-19952.

Parvin, J.D. and P.A. Sharp. 1993. DNA topology and a minimal set of basal factors for transcription by RNA polymerase II. Cell 73: 533-540.

Ptashne, M. 1986. Gene regulation by proteins acting nearby and at a distance. Nature 322: 697-699.

Rippe, K., P.H. von Hippel, and J. Langowski. 1995. Action at a distance: DNA-looping and initiation of transcription. Trends Biol. Sci. 20: 500-506.

Schild, C., F.-X. Claret, W. Wahli, and A.P. Wolffe. 1993. A nucleosome-dependent statis loop potentiates estrogenregulated transcription from the Xenopus vitellogenin B1 promoter in vitro. EMBO I. 12: 423-433.

Schöler, H.R. and P. Gruss. 1985. Cell type-specific transcriptional enhancement in vitro requires the presence of transacting factors. EMBO J. 4: 3005-3013.

Schultz, M.C., S.Y. Choe, and R.H. Reeder. 1993. In vitro definition of the yeast RNA polymerase I enhancer. Mol. Cell. Biol. 13: 2644-2654.

Sergeant, A., D. Bohmann, H. Zentgraf, H. Weiher, and W. Keller. 1984. A transcription enhancer acts in vitro over distances of hundreds of base-pairs on both circular and linear templates but not on chromatin-reconstituted DNA. J. Mol. Biol. 180: 577-600.

Shi, Y., E. Seto, L-S. Chang, and T. Shenk. 1991. Transcriptional repression by YY1 a human GLI-krüppel-related protein, and relief of repression by adenovirus E1A protein. Cell 67: $377-$ 388.

Strominger, J. 1989. Developmental biology of T cell receptors. Science 244: 943-950.

Thanos, D. and T. Maniatis. 1995. Virus induction of human IFN beta gene expression requires the assembly of an enhancesome. Cell 83: 1091-1100.

Walters, M.C., S. Fiering, J. Eidemiller, W. Magis, M. Groudine, and D.I. Martin. 1995. Enhancers increase the probability but not the level of gene expression. Proc. Natl. Acad. Sci. 92: 7125-7129.

Wang, J.C. and G.N. Giaever. 1988. Action at a distance along a DNA. Science 240: 300-304.

Wasylyk, B. 1988. Enhancers and transcription factors in the control of gene expression. Biochim. Biophys. Acta 951: 1735.

Waterman, M.L., W.H. Fischer, and K.A. Jones. 1991. A thymusspecific member of the HMG protein family regulates the human $\mathrm{T}$ cell receptor $\mathrm{C} \alpha$ enhancer. Genes \& Dev. 5: 656669.

Wildeman, A.G., P. Sassone-Corsi, T. Grundström, M. Zenke, and P. Chambon. 1984. Stimulation of in vitro transcription from the SV40 early promoter by the enhancer involves a specific trans-acting factor. EMBO T. 3: 3129-3133.

Winoto, A. and D. Baltimore. 1989. A novel, inducible and T cell-specific enhancer located at the $3^{\prime}$ end of the $\mathrm{T}$ cell receptor $\alpha$ locus. EMBO I. 8: 729-733.

Wu, H.-Y., J. Tan, and M. Fang. 1995. Long-range interaction between two promoters: Activation of the leu- 500 promoter by a distant upstream promoter. Cell 82: 445-451.

Yang, Y., T.P. Westcott, S.C. Pedersen, I. Tobias, and W.K. Olson. 1995. Effects of localized bending on DNA supercoiling. Trends Biol. Sci. 20: 313-319. 


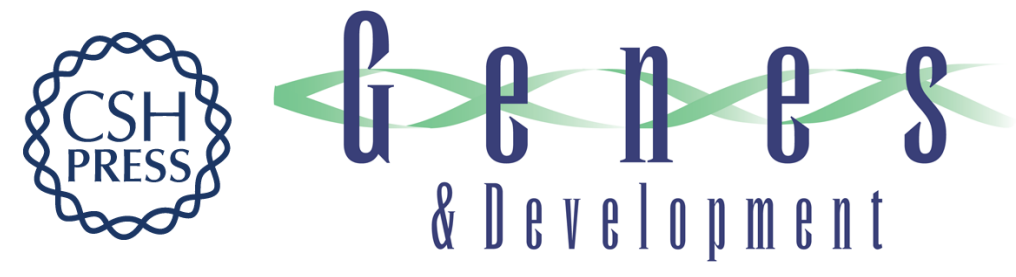

\section{An HMG I/Y-containing repressor complex and supercoiled DNA topology are critical for long-range enhancer-dependent transcription in vitro.}

R Bagga and B M Emerson

Genes Dev. 1997, 11:

Access the most recent version at doi:10.1101/gad.11.5.629

References This article cites 40 articles, 17 of which can be accessed free at: http://genesdev.cshlp.org/content/11/5/629.full.html\#ref-list-1

License

Email Alerting Receive free email alerts when new articles cite this article - sign up in the box at the top Service right corner of the article or click here.

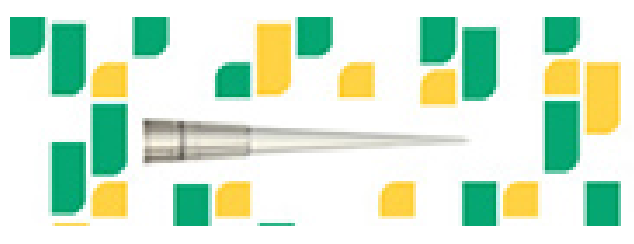

Focused on your science. 